\title{
Tuberculous tenosynovitis presenting as finger drop: a case report and a systematic review of the literature
}

\author{
Jayadev Chandrasekharan 1 \\ Senthil Nathan Sambandam ${ }^{1}$ \\ Sreehari Cheriyakara ${ }^{2}$ \\ Varatharaj Mounasamy ${ }^{3}$
}

1 Department of Orthopaedics, K.G. Hospital and

Postgraduate Medical Institute, Tamil Nadu, India

2 Department of Orthopaedics, ACME, Kannur, Kerala, India

3 VCU Medical Center Ambulatory Care Center, Richmond, Virginia, USA

Corresponding author:

Jayadev Chandrasekharan

Department of Orthopaedics, K.G. Hospital and Postgraduate Medical Institute, Tamil Nadu

Arts college road

641018 Tamil Nadu, India

E-mail:drkjayadev@gmail.com

\section{Summary}

Background: Isolated tuberculous tenosynovitis and bursitis are rare among musculo-skeletal tuberculosis, but it is one of the major causes for chronic tendon sheath infection in developing countries. In hand, it is usually presented as a compound palmer ganglion (radio ulnar bursa), tenosynovitis of the flexer tendon sheaths and very few cases of tubercular tenosynovitis affecting the extensor tendons also are reported.

Case presentation: We are reporting a rare case of tuberculous extensor tenosynovitis with rupture of the extensor digitorum tendon in an elderly Indian man. This case report and review meets the ethical standard of the journal.

Conclusion: Delayed diagnosis of tuberculous tenosynovitis is due to numerous differential diagnoses and slow progression. For all chronic synovitis around the wrist, consider Mycobacterial infection as an important differential diagnosis. Early diagnosis, radical excision combined with multidrug antituberculous therapy gives good functional results.

KEY WORDS: antituberculous treatment, caseous necrosis, extensor digitorun tendon, melon-seed bodies, tuberculous tenosynovitis.

\begin{abstract}
Introduction
Musculoskeletal tuberculosis accounts for only $10 \%$ of TB cases ${ }^{1}$. Isolated tuberculous polymyositis, tenosynovitis and bursitis are rare and constituting only $1 \%$ of musculo-skeletal tuberculosis. It is one of the major reasons for chronic tendon sheath infection in developing countries despite the fact that tendon sheath is an uncommon target for Mycobacterium². It generally affects the tendon sheaths of hand and wrist and usually presents as compound palmar ganglion (radio ulnar bursa) and tenosynovitis of the flexer tendon sheaths. The tuberculous teno-synovitis usually mimics many other conditions which lead to delay in diagnosis and more complications ${ }^{3}$. Tuberculous involvement of the extensors tendons of the hand and wrist is a rare condition and can pose a major diagnostic challenge in routine clinical setup. In this report we are presenting a case of tuberculous extensor tenosynovitis of the wrist with rupture of the extensor digitorum tendon.
\end{abstract}

\section{Case report}

A 60 year-old-male patient presents with a progressive swelling over the dorsum of right wrist of 4 months duration. Initially there was only a single swelling and 1 month after he noted another swelling just proximal to that. There was mild dull aching type of pain. Three months after the appearance of the swelling he had difficulty in extending the right middle and ring finger.

He does not have any history of constitutional symptoms like loss of weight, loss of appetite, evening rise of temperaure. There was no past history of pulmonary tuberculosis and no family history of tuberculosis. No history of local steroid injection in the right hand or wrist. No history of other medical co-morbidities. On examination, there were two swellings measuring $3 \times 2.5 \mathrm{~cm}$ and $2.5 \times 2 \mathrm{~cm}$ which was non-tender and there was no local rise in temperature and it's a boggy swelling with well defined margins and slipping edges and it was fluctuant with transverse mobility and it was non-pulsatile and non trans-illuminant. There was no active extension of ring and middle finger at MCP joint indicating a possible rupture of extensor digitorum tendon slip of middle and ring finger (Fig. 1). All other systemic examinations were normal. All routine blood investigations were normal. Erythrocyte sedimentation rate was $10 \mathrm{~mm} / \mathrm{hr}$. Chest X-ray and X-ray of wrist was normal. Ultrasonography 


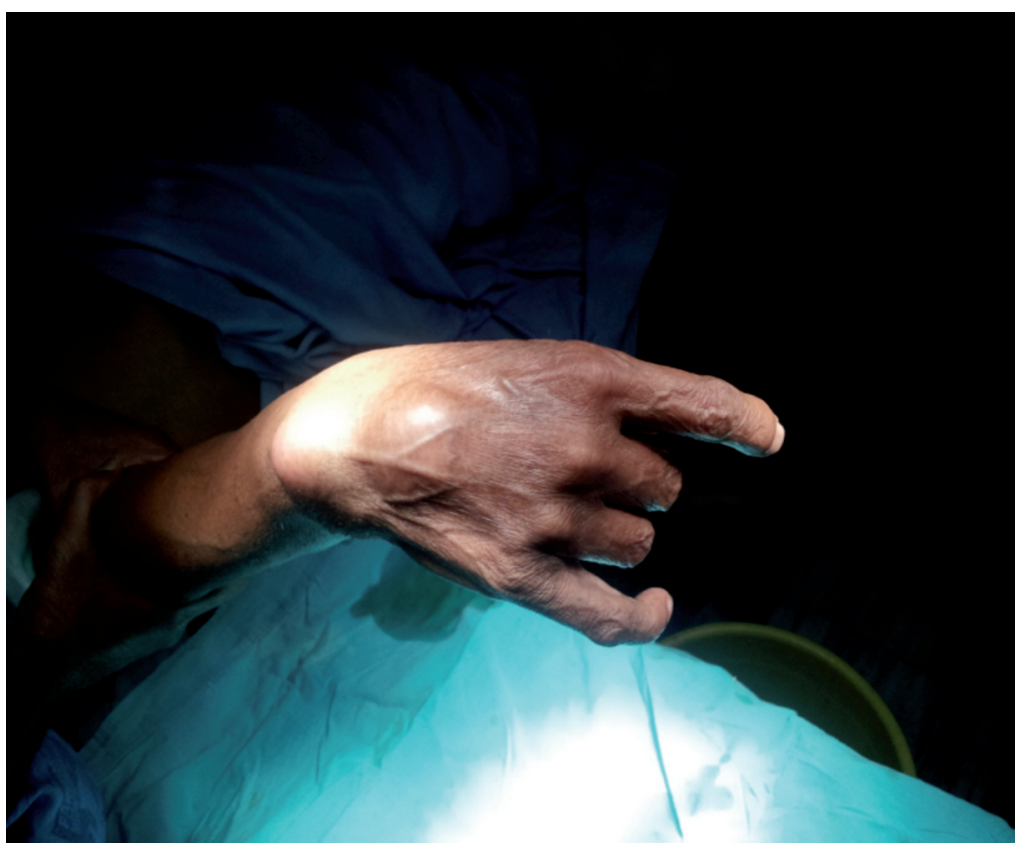

Figure 1. Showing finger drop of middle and ring finger.

showed thickening and decreased echogenicity of extensor digitorum tendons with minimal fluid collection around tendon sheath and thickening of the synovial sheath with minimal vascularity. Since the patient was presented with features of tendon rupture and inflammation especially he was a smoker and he was from a low socioeconomic group we thought about tuberculous tenosynovitis as a major differential diagnosis. The aspiration of the fluid may be inconclusive because only minimal amount of fluid was noticed in the ultrasonography. Patient was also presented with tendon rupture and it requires exploration and repair. Thus we elected to proceed with exploration and biopsy.

An open excision biopsy, synoviectomy and debridement was done under interscalene block. The two swellings were communicating under the extensor retinaculum (Fig. 2). There were numerous melonseed (rice-seed) bodies (Fig. 3) inside the exensor tendon sheath with complete rupture of extensor tendons of middle and ring finger (Fig. 4).

Melon-seed bodies along with the sheath were excised and removed in total and thorough debridement and irrigation of the wound was done. End to End repair of the extensor tendons was accomplished without much difficulty, retinaculum was repaired and wound was closed over a drain. A below-elbow posterior splint was applied with wrist and fingers in extension. Drain removed with in 48 hours, suture removal done on $10^{\text {th }}$ day. Histopathology showed synovial tissue and fibrocollagenous tissue with multiple

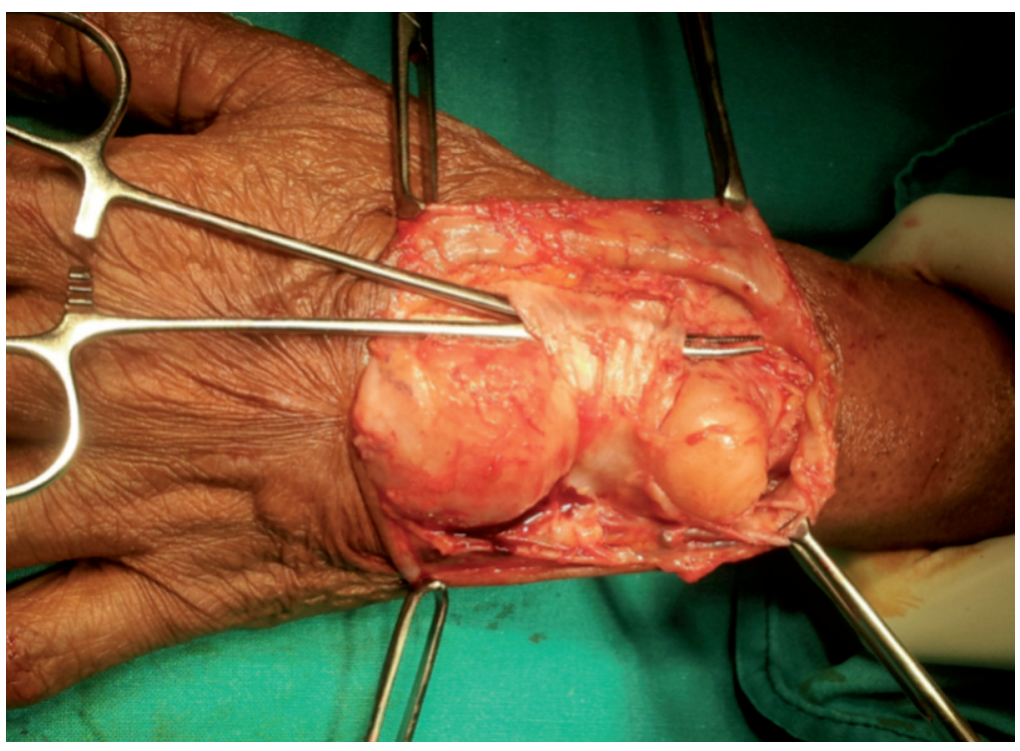

Figure 2. The two swellings were communicating under the extensor retinaculum. 


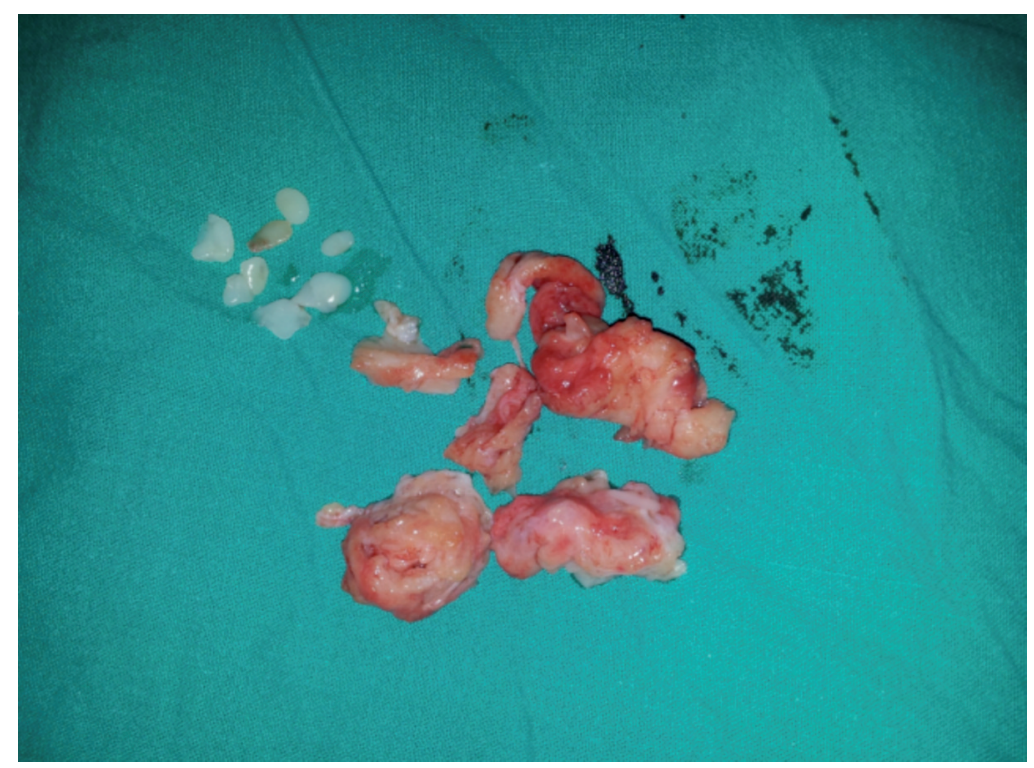

Figure 3. Melon-seed bodies along with excised tendon sheath.

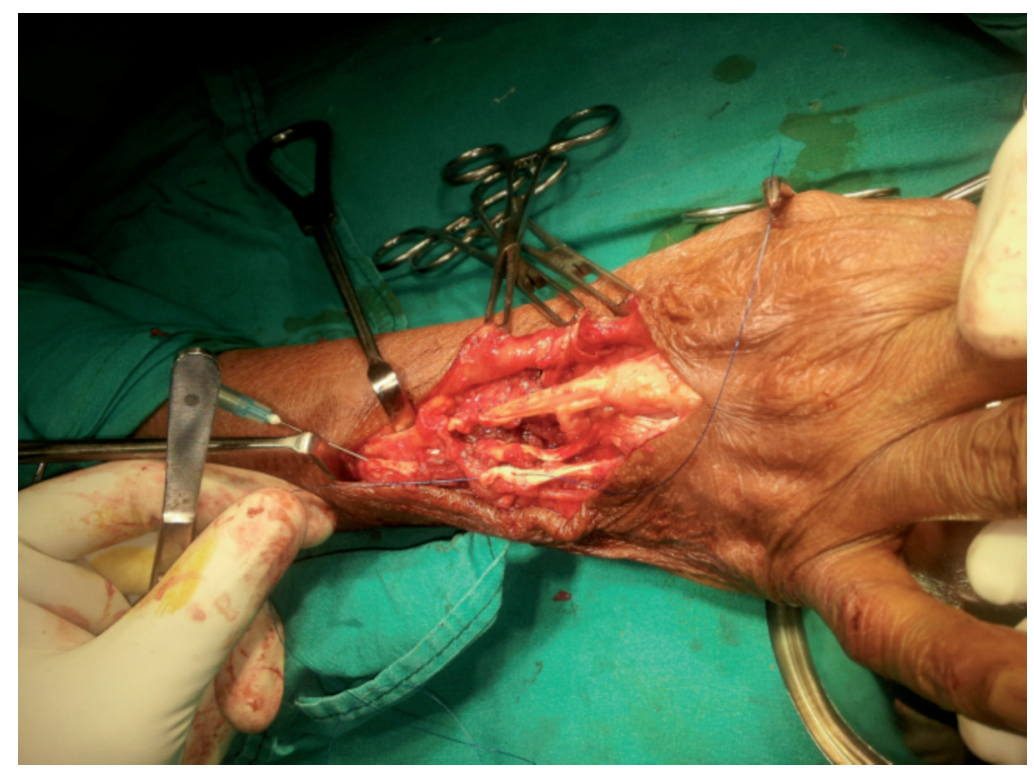

Figure 4. Complete rupture of extensor tendons of middle and ring finger.

epitheloid aggregates, Langerhans giant cells and foci of necrosis (Fig. 5). The below-elbow posterior splint was kept for 4 weeks. Intermittent mobilization within the splint was started for the following 2 weeks. Subsequently, the splint was removed and the patient was returned to normal work in 3 months. His finger extensor power was near normal at $3^{\text {rd }}$ month followup. Antituberculous treatment was started immediately after confirming the diagnosis by histopathology. The patient was received $300 \mathrm{mg}$ of isoniazid, 600 $\mathrm{mg}$ of rifampicin, $800 \mathrm{mg}$ of ethambutol, $1500 \mathrm{mg}$ of pyrazinamide daily for 2 months followed by isoniazid and rifampicin for 7 more months. Patient was evaluated monthly till the chemotherapy finished. There was no sign of recurrence in the final follow up at $40^{\text {th }}$ month (Fig. 6). The protocol and goals of the study which was approved by Ethics committee of the institution, were explained to the patient who signed the consent form. Current study meets the ethical standards of Muscles, Ligaments and Tendons Journal ${ }^{4}$.

\section{Discussion}

In 1756, Acrel first described tuberculous involvement of tendons in the form of tenosynovitis ${ }^{5}$. Musculoskeletal tuberculosis affecting the tendon, bone and bursa, is rare among extrapulmonary tuberculosis and accounts for about $1.3 \%$ of cases ${ }^{6}$. Foot and ankles involvement is less commonly reported. In the hand and wrist, the flexor tendon sheath and radioulnar bursae (the compound palmar ganglion) are the 


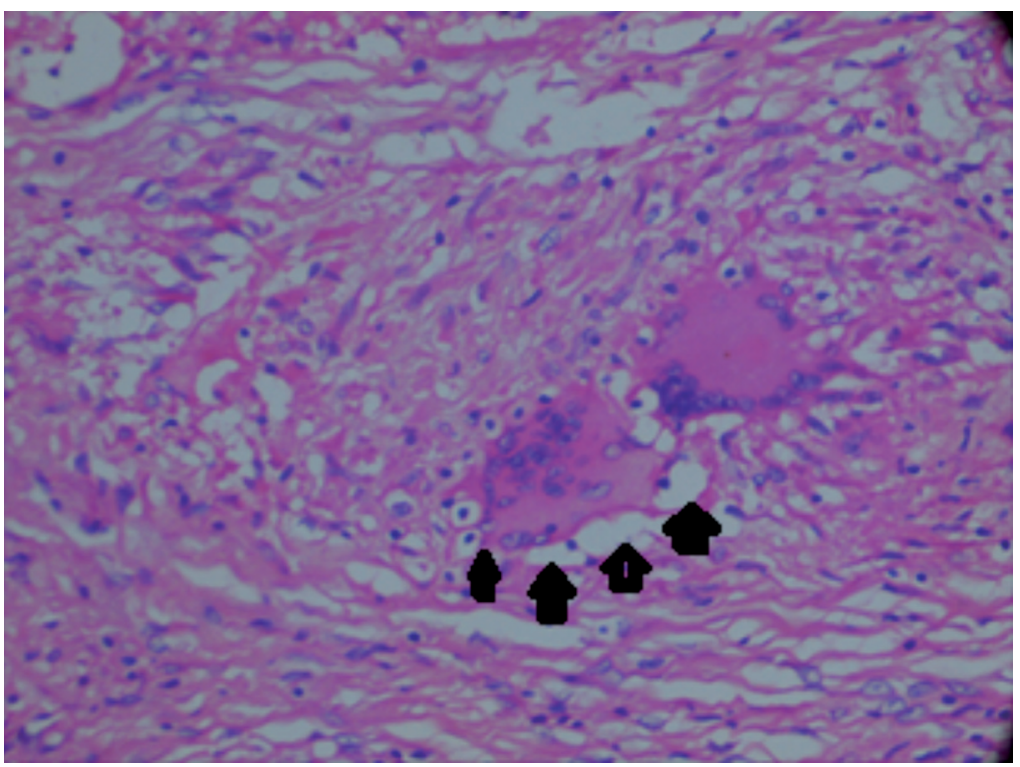

Figure 5. Microscopy shows granulomatous inflammation, epithelioid cell granuloma with central caseous necrosis (arrowheads).
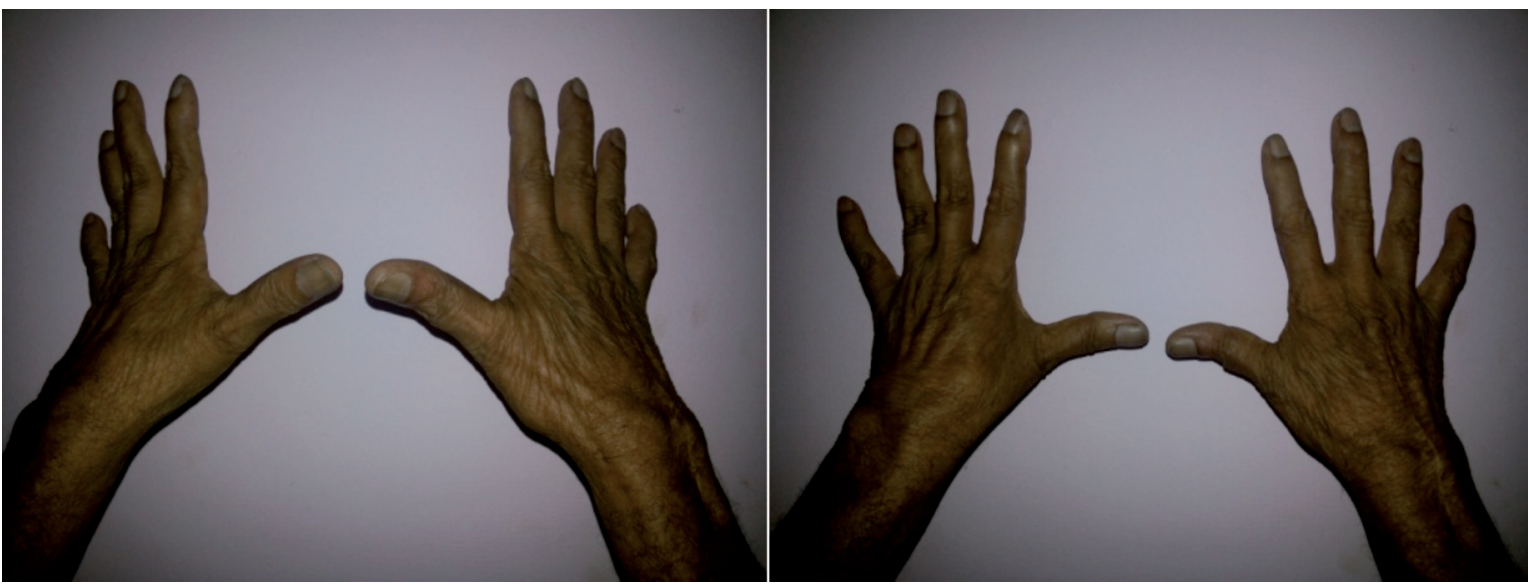

Figure 6. No recurrence in the final follow up at 40th month.

most common sites. However, the extensor compartment of the wrist and digital flexor sheaths also affected less commonly ${ }^{7-10}$. Recently there are case reports of multifocal tenosynovitis also ${ }^{10}$.

Tuberculus tenosynovitis is most likely due to a direct inoculation from a joint infection, adjacent bone or seeding from a tuberculous lesion in the pleura, lung or genitourinary system. The main precipitating factors are trauma, malnutrition, immunosuppression, alcoholism, overuse of the joint, age more than 60 years, low socioeconomic status and steroid injections. The usual presentation is an insidious onset, slowgrowing, painless or mildly painful mass along the inflamed tendon. In rare situation, when the treatment is delayed, it may present as swelling with Tendon ruptures ${ }^{8-11}$. In the index case patient was from a low socio-economic group and presented as insidius onset slow growing swelling with mild dull aching type of pain with extensor tendon rupture. The diagnosis can be easily delayed because of non-specificity of clinical signs. Pa- tients may present as carpal tunnel syndrome and a non-specific synovitis mimicking De Quervain's disease or tophaceous gout ${ }^{6,8}$. Main differential diagnoses of tuberculous tenosynovitis are pyogenic infection, foreign body tenosynovitis, brucellosis, other mycobacterial infections, rheumatoid arthritis, sarcoidosis, pigmented villonodular synovitis of the tendon sheath, gouty arthritis and fungus infection 8,12-14.

Histologically, tuberculous tenosynovitis consists of three stages. In early stages, there is vascular granulation tissue infiltration in the tendon. In the later stage, fibrous tissues obliterates the tendon sheath associated with caseation leads to rice body formation and there may be fluid collection within the tendon sheath also. In the last stage, tendon is replaced by a strands of tissue which leads to spontaneous rupture of the tendon. If there is no fibrous tissue formation to control the pathologic process and to promote healing, there may be extensive caseous necrosis which leads to superimposed secondary infection and sinus forma- 
tion $8,11,13$. Eventhough, granulomas (non-caseating or caseating) occur in almost all cases "melon seeds" or "rice bodies" are seen in only $50 \%$ of tuberculous tenosynovitis cases ${ }^{12,13}$. In our case there was rice body formation with extensive granulation tissue formation and histologically, epithelioid cell granuloma with caseous necrosis. Reise, first described the formation of rice bodies in $1895^{15}$. It is also seen in rheumatoid arthritis, seronegative arthritis, nonspecific arthritis, SLE, atypical mycobacterial infections and less commonly osteoarthritic joints also.

All the laboratory findings except erythrocyte sedimentation rate is usually normal ${ }^{7}$. MRI features may be synovial thickening with vascularization, reactive inflammation around the tendon with swelling of the tendon. In contrast to acute suppurative tenosynovitis, fluid in the synovial sheath is relatively less and this is the characteristic of tuberculous tenosynovitis $^{13}$. The diagnosis is either by demonstrating the presence of the tubercle bacillus by microscopy, culture or by histopathology ${ }^{16-20}$. In this case all blood investigations and culture were normal. The patient was not affordable for MRI, but histopathology was diagnostic for tuberculous tenosynovitis.

There was only a limited number of cases reported in the literature (Tab. I). Pimm et al., in 1957, reported 52 cases of tuberculous tenosynovitis. Among these, ten lesions from the common extensor sheath of hand. They reported 5 recurrences from these 10 cases after radical excision and 1 case of extensor tendon rupture ${ }^{9}$. From Kanavel's files Mason, reported 10 instances of rupture or impending tendon rupture in 21 available records of tuberculous tenosynovitis of the hand ${ }^{10}$. Regnard et al. analyzed 5 cases of tuberculus flexor tenosynovitis of the hand. They concluded that local steroid therapy may be a causative factor and synovectomy combined with antituberculus treatment gives good fucnctional results but local recurrence is not rare ${ }^{21}$. A case of tuberculus extensor tenosynovitis with EPL rupture reported by Lall et al. found that, there was good functional outcome after debridement, synovectomy combined with 10 months of antituberculous therapy ${ }^{22}$. Cramer et al. evaluated the outcome of two cases of tuberculus tenosynovitis of the wrist. Both cases had recurrence. They concluded that tuberculous tenosynovitis needs a combined surgical debridement and chemotherapy $^{5}$. Dlimi et al. reported 10 cases of tuberculous tenosynovitis. All the cases were managed by biopsy followed by only anti tubercular treatment and the outcome was good in all patients ${ }^{23}$. Güner et al. reported 3 cases of tuberculous tenosynovitis of the wrist caused by mycobacterium bovis. All the cases were managed by surgical debridement and synoviectomy followed by 9 months of antitubercular treatment. All the patients were doing well during the final follow up ${ }^{24}$. Özcelik et al. reported 3 cases of tenosynovitis of the wrist. All the cases had biopsy followed by 9 months of ATT. There were no cases of recurrence in the final follow up in all cases ${ }^{25}$.

There are some controversies among the treatment options available for tuberculosis of hand and wrist (Tab. II). Bush et al. points outs that, the chance of recurrence is more for only surgical treatment without antibacillary treatment ${ }^{26}$. Cramer et al. ${ }^{5}$, Bush et al. ${ }^{26}$, and Regnard et al. ${ }^{21}$ found out good results with surgical debridement combined with antitubercular drugs. Similar type of treatment option was also suggested by other Authors also8,9,12,16,20,27,28. A comparative study between chemotherapy alone and surgery-chemotherapy combination by Visuthikosol et al. ${ }^{33}$ found that, no recurrence occurred in both groups. Kotwal et al. ${ }^{17}$ had reported good clinical outcome with only chemotherapy; they suggested debridement only for the non-responding cases. Dlimi et al. ${ }^{23}$ reported successful outcome for conservative treatment with antitubercular drugs, immobilization and rehabilitation. Considering the duration of chemotherapy, many Authors were recommending at least 9 months of antitubercular drugs ${ }^{22,24,25}$.

Regarding surgical debridement, some Authors prefer debridement with tendon sheath excision, while others suggest only decompression of the tendon sheath without excision and debridement of the surrounding

Table I. Reported case of tuberculous tenosynovitis.

\begin{tabular}{|c|c|c|c|c|}
\hline Author & Journal, Year & Number & Follow-up & Recurrence \\
\hline Ozcelik et al. ${ }^{25}$ & $\begin{array}{l}\text { Acta Orthop Traumatol } \\
\text { Turc, } 2006\end{array}$ & 3 & $\begin{array}{l}21 \text { months } \\
26 \text { months } \\
16 \text { months }\end{array}$ & 0 \\
\hline Güner et al. ${ }^{24}$ & $\begin{array}{l}\text { Plast Reconstr Surg Glob } \\
\text { Open, } 2014\end{array}$ & 3- & $\begin{array}{l}48 \text { months } \\
26 \text { months } \\
12 \text { months }\end{array}$ & 0 \\
\hline Dlimi et al. ${ }^{23}$ & Chir Main. 2011 & 10 & - & - \\
\hline Pimm et al. ${ }^{8}$ & JBJS, 1957 & 10- extensor tenosynovitis & 1 to 27 years & 5 \\
\hline Lall et al. ${ }^{22}$ & $\begin{array}{l}\text { Journal of Medical Case } \\
\text { Reports } 2009\end{array}$ & 1- extensor tenosynovitis & 12 months & 0 \\
\hline Regnard et al. ${ }^{21}$ & J Hand Surg Br. 1996 & 5- flexor tenosynovitis & - & 0 \\
\hline
\end{tabular}


Table II. Treatment options available in the literature.

\begin{tabular}{|c|c|c|c|c|}
\hline Author & Journal, Year & Number & Treatment & Recurrence \\
\hline Kotwal et al. ${ }^{17}$ & J Bone Joint Surg [Br] 2009 & 32 & Chemotherapy & 8 \\
\hline Visuthikosol et al. ${ }^{28}$ & Ann Plast Surg. 1996 & 23 & $\begin{array}{l}2 \text { groups } \\
\text { Only Chemotherapy/ } \\
\text { Chemotherapy+surgery }\end{array}$ & 0 \\
\hline Bush et al. ${ }^{26}$ & J Hand Surg Am. 1984 & 11 & Chemotherapy+surgery & 1 \\
\hline Cramer et al. ${ }^{5}$ & Clin Orthop Relat Res. 1991 & 2 & $\begin{array}{l}\text { 1-only surgery } \\
\text { 1-only chemotherapy }\end{array}$ & 2 \\
\hline Dlimi et al. ${ }^{23}$ & Chir Main. 2011 & 10 & Chemotherapy & - \\
\hline Regnard et al. ${ }^{21}$ & J Hand Surg Br. 1996 & 5- flexor tenosynovitis & Chemotherapy+surgery & - \\
\hline
\end{tabular}

tissue $e^{7,9,12,19}$. TB tenosynovitis has a tendency for local recurrence. Usually more than $50 \%$ of cases recurring within a year of treatment ${ }^{21}$. So all the cases requires close follow-up. The index case was treated with synoviectomy and debridement of involved soft tissue with repair of extensor tendon followed by 9 months of antitubercular treatment. There was no recurrence at $40^{\text {th }}$ month of follow-up.

\section{Conclusion}

Tuberculous tenosynovitis of the hand and wrist are rare. Delay in the diagnosis leads to complications like rupture of the tendon. The diagnosis is by demonstrating the presence of mycobacterium either by microbiology or by histopathology. Tuberculous tenosynovitis has a tendency for local recurrence. Early diagnosis and radical excision with synoviectomy and debridement of the infected tissues combined with antituberculous multidrug therapy gives good results and prevents the chance of recurrence.

\section{Disclosure}

Tuberculous tenosynovitis presented as finger drop: case report and review meets the ethical standards of the journal.

\section{Consent}

Written informed consent was obtained from the patient for publication of this case report and any accompanying images.

\section{Conflict of interest}

Each Author certifies that, no benefits in any form have been received or will be received from a commercial party related directly or indirectly to the subject of this study.

\section{References}

1. Lee SH, Abramson SB. Infections of the musculoskeletal system by M. tuberculosis, In Tuberculosis 4th edition. Edited by: Rom WN, Garay SM. New York, NY: Little, Brown and Company. 1996;635-644.

2. Albornoz MA, Mezgarzedeh $\mathrm{M}$, Neumann $\mathrm{CH}$, Myers. Granulomatous tenosynovitis: A rare musculoskeletal manifestation of tuberculosis. Clin Rheumatol. 1998;17:166-169.

3. Jackson RH, King JW. Tenosynovitis of the hand: a forgotten manifestation of tuberculosis. Rev Infect Dis. 1989;11:616618.

4. Padulo J, Oliva F, Frizziero A, Maffulli N. Muscles, Ligaments and Tendons Journal. Basic principles and recommendations in clinical and field science research: 2016 Update. MLTJ. 2016;6(1):1-5.

5. Cramer K, Seiler JG, Milek MA. Tuberculous tenosynovitis of the wrist: two case reports. Clin Orthop Relat Res. 1991;(262): 137-140.

6. Lakhanpal S, Linscheid RL, Ferguson RH, Ginsburg WW. Tuberculous fasciitis with tenosynovitis. 1987;14(3):621-624.

7. Bickel WH, Kimbrough RF, Dahlin DC. Tuberculous tenosynovitis. J Am Med Assoc. 1953;151(1):31-35.

8. Jaovisidha $S$, Chen $C$, Ryu KN, Siriwongpairat P, Pekanan P, Sartoris DJ, Resnick D. Tuberculous tenosynovitis and bursitis: imaging findings in 21 cases. Radiology. 1996;201:507-513.

9. Pimm LH, Waugh W. Tuberculous tenosynovitis. J Bone Joint Surg Br. 1957;39-B(1):91-101.

10. Mason ML. Tuberculous tenosynovitis of the hand: A study of thirty-three cases of tuberculous tenosynovitis. Surg Gynecol Obstet. 1934;59:363-369.

11. Burkhardt E. Chronic diseases of the synovial sheath (from hand surgery consulting hour). Beitr Orthop Traumatol. 1972;19:377-391.

12. Aboudola S, Sienko A, Carey RB, Johnson S. Tuberculous tenosynovitis. Hum Pathol. 2004;35(8):1044-1046.

13. Hoffman KA, Bergman AG, Hoffman DK, Harris DP. Tuberculosis tenosynovitis of the flexor tendons of the wrist: MR imaging with pathologic correlation. Skeletal Radiol. 1996;25:186188.

14. Hsu CY, Lu HC, Shih TT. Tuberculous infection of the wrist: MRI features. AJR Am J Roentgenol. 2004;183(3):623-628.

15. Reise H. Die Reiskörpschen in tuberculserkrankensynovalsacken. Deutsche Zeitschrift für Chirurgie. 1895;42:1.

16. Benkeddache $Y$, Sidhoum SE, Derridj A. Various aspects of tuberculosis of the hand: apropos of a series of 45 cases. Ann Chir Main. 1988;7(2):166-175. 